\title{
An attempt at presymptomatic diagnosis of gastric carcinoma in pernicious anaemia
}

\author{
T. H. BOON, R. O. K. SCHADE, G. D. MIDDLETON ${ }^{1}$, AND M. F. REECE \\ From the Royal Victoria Infirmary, Newcastle upon Tyne, \\ and the Department of Medicine, University of Durham
}

EDITORIAL SYNOPSIS Patients with pernicious anaemia were submitted to regular cytological examination at six-monthly intervals over a period of three years, and malignant cells were reported in only two patients, one being shown to have a simple polyp and the other an inoperable fundal neoplasm with peritoneal metastases. The study is being continued.

In classical pernicious anaemia there is said to be an approximately three-fold increase in the incidence of gastric carcinoma (Kaplan and Rigler, 1945; Mosbech and Videback, 1950). The interval between the diagnosis of pernicious anaemia and the discovery of evidence of neoplasm has been reported to be several years and sometimes more than 10 years (Bourne, 1948; Washburn and Rozendaal, 1938). We have regularly followed nearly 200 patients in an attempt to determine whether periodic cytological examinations would enable us to diagnose early or asymptomatic cases of gastric carcinoma. Although some authors (Burnett, MacFarlane, Park, and Kay, 1960) have criticized exfoliative gastric cytology because of the high incidence of false negative results, Reece, Boon, and Schade (1961) have reported cases detected by cytology which were undiagnosed radiologically.

\section{METHODS}

In 1959, 398 patients who had been treated for pernicious anaemia were asked to participate in the survey. The age and sex distributions of these patients are shown in Table I. Of these, 105 failed to keep their initial appointment and 11 were rejected, so that 282 patients entered the survey and of these 20 have withdrawn because of age, intercurrent illness, or personal iriconvenience, and a further 73 have defaulted. Patients attended at six-monthly intervals, were questioned as to the presence of gastric symptoms, and were then examined

${ }^{1}$ Now Senior Medical Registrar, Radcliffe Infimary, Oxford. clinically. Gastric cytology was carried out in the manner described by Schade (1958) and slides were examined by him. Eight hundred and eighteen cytological examinations were done; the number on each patient is shown in Table II and the length of follow-up in Table III. The interval between the diagnosis of the patients' anaemia and the commencement of follow-up is shown in Table IV. Four of the patients contacted had already been operated on for gastric carcinoma.

TABLE I

\begin{tabular}{lcrrrrrrr}
\multicolumn{8}{c}{ AGE AND SEX DISTRIBUTION } \\
Age $(y r)$. & $30-40$ & $40-50$ & $50-60$ & $60-70$ & $70-80$ & $80+$ & Total \\
\hline Males & 2 & 7 & 17 & 26 & 32 & 6 & 90 \\
Females & 4 & 14 & 39 & 62 & 65 & 8 & 192
\end{tabular}

TABLE II

NO. OF EXAMINATIONS ON EACH PATIENT

$\begin{array}{lrrrrrrrr}\text { No. of patients } & 71 & 49 & 35 & 56 & 40 & 21 & 7 & 3 \\ \text { No. of examinations } & 1 & 2 & 3 & 4 & 5 & 6 & 7 & 8\end{array}$

\section{TA BLE III}

Years

Patients LENGTH OF FOLLOW-UP $\begin{array}{lll}0-1 & 1-2 & 2-3 \\ 21 & 114 & 147\end{array}$

RESULTS

Atypical cells were reported on one occasion in four patients. In three of these gastroscopy, barium meal, and further cytology were all normal and they have

TABLE IV

INTERVAL BETWEEN DIAGNOSIS AND START OF FOLLOW-UP

Years since diagnosis of pernicious anaemia

No. of patients

$\begin{array}{lllllllllllllllllllll}1 & 2 & 3 & 4 & 5 & 6 & 7 & 8 & 9 & 10 & 11 & 12 & 13 & 14 & 15 & 16 & 17 & 18 & 19 & 20 & 20 \dashv \\ 9 & 17 & 35 & 21 & 38 & 19 & 14 & 11 & 11 & 14 & 11 & 7 & 15 & 4 & 13 & 9 & 3 & 5 & 3 & 3 & 33\end{array}$


remained well and symptom free to date. In the fourth patient, who was also symptom free, later cytological examinations were normal but the haemoglobin level fell and occult blood was found in the stools. A barium meal showed a fixed hiatus hernia and some mucosal irregularity on the lesser curve suggestive of a gastric neoplasm. Laparotomy disclosed a well-differentiated adenocarcinoma of the body and pyloric end of the stomach which was inoperable.

Malignant cells have been reported in two patients. In one they were reported on one occasion, but in a further five gastric washings were normal, as was a barium meal. Gastroscopy demonstrated a gastric polyp, which on excision proved benign. The neighbouring gastric mucosa showed chronic, atrophic gastritis; this patient is well two years later. A second patient was found to have malignant cells in his first gastric washing. He was then well, physical examination was negative, and his haemoglobin level was $107 \%$. Radiological appearances were, however, suggestive of a leather-bottle stomach and at laparotomy there was a large inoperable fundal neoplasm with multiple peritoneal metastases.

\section{DISCUSSION}

Specimens for gastric examination cannot be obtained without the discomfort of intubation. Nevertheless 181 of 282 patients are still attending after nearly three years. The discovery of atypical or malignant cells may precede other indications of a gastric carcinoma and so lead to an earlier diagnosis than if one awaited the usual presenting symptoms. Whether the time taken over the examinations and the inconvenience to the patients is justified by the results may become more apparent as this investigation proceeds.

We wish to thank all the consultant staff of the Royal Victoria Infirmary for allowing us to use their case records, and Dr. R. B. Thompson for his criticisms. Two of us (G.D.N. and M.F.R.) were in receipt of a grant from the British Empire Cancer Campaign.

\section{REFERENCES}

Bourne, W. A. (1948). Cancer of the stomach in Addison's anaemia. Brit. med. J., 1, $92-94$.

Burnett, W. MacFarlane, P. S., Park, S. D. S., and Kay, A. W. (1960). Carcinoma of the stomach: an evaluation of diagnostic methods including exfoliative cytology. Ibid., 1, 753-755.

Kaplan, H. S., and Rigler, L. G. (1945). Pernicious anaemia and carcinoma of the stomach-autopsy studies concerning their interrelationship. Amer. J. med. Sci., 209, 339-348.

Mosbech, J., and Videback, A. (1950). Mortality from and risk of gastric carcinoma among patients with pernicious anaemia. Brit. med. J., 2, 390-394.

Reece, M. F., Boon, T. H., and Schade, R. O. K. (1961). Exfoliative gastric cytology: its evaluation in the diagnosis of carcinoma of the stomach. Lancet, 2, 1163-1164.

Schade, R. O. K. (1958). Exfoliative cytology of gastric carcinoma. Brit. med. J., 1, 743-744.

Washburn, R. N., and Rozendaal, H. M. (1938). Gastric lesions associated with pernicious anaemia. Ann. intern. med., 11, 2172-2180. 